\title{
BALANCING OF WIND ENERGY USING OIL-SHALE BASED POWER PLANTS AT ERRONEOUS WIND FORECAST CONDITIONS
}

\author{
I. PALU*, R. OIDRAM, M. KEEL, H. TAMMOJA \\ Tallinn University of Technology \\ Ehitajate tee 5 \\ 19086 Tallinn, Estonia
}

\begin{abstract}
During the negotiations with EU, Estonia was set an indicative target to increase the share of renewable energy sources in the electricity production to $5.1 \%$ of inland consumption by the year 2010. Similarly to the rest of Europe, one of the main means to achieve this target is to install wind turbines. The current paper analyses the capability of existing oil-shale power plants to cover differences between forecasted and actual generation of wind energy and shows that participation of fossil fuel-based power plants in the compensation of fluctuating production of wind turbines eliminates part of the expected positive effect of wind energy.
\end{abstract}

\section{Introduction}

In the beginning of the year 2009, it was stated that the USA has become the leading country in the field of wind energy, leaving the previously leading country Germany as the second and Spain as the third. If China continues to increase erection of new wind energy installations (China's total capacity doubled for the fourth year in a row), China would be well on its way to overtake Germany and Spain to reach the second place in terms of total wind power capacity in 2010 [1]. It must be instantly reminded that despite of the large numbers of wind installations in the USA and China, the share of fluctuating energy sources from total installed capacity is still modest but growing. Therefore, increasing the share of renewable energy in the electricity production is an important issue everywhere in the world and is not focused solely on Europe. The characteristic of wind energy, particularly its stochastic nature, is considered a drawback for large-scale use of wind energy, and fulfilling the expectations of consumers requires balancing units in co-operation [2]. The best way to manage wind energy fluctuations is to cover it with other renewable energy sources, such as hydro power plants.

\footnotetext{
* Corresponding author: e-mail address ivo.palu@ttu.ee
} 
Unfortunately there are more and more new wind turbine generators (WTGs), but no new hydropower plants, and the existing capacity will be scarce. In the year 2008 according to [3] $43 \%$ of new installations in Europe were wind turbines and only $3 \%$ were hydro power plants. It is stated in [4] that the regulation of wind power is not yet a problem for a hydro-dominated power system, but other issues are likely to arise before regulation. In case all the fluctuations of wind power can be compensated with other renewable energy sources, the integration of WTGs does not cause additional emission, and the environmental gain is linearly proportional to the produced amount of electricity. The options for balancing are limited, and that leaves the balancing to traditional power generating units like gas and other fossil fuel based power plants, which are reliable and controllable, but this is no pollution-free way to balance wind energy. The latter is not a phenomenon specific only to Estonia.

The use of wind energy is one of the most attractive options in the countries with long coastline and islands like Estonia. In spite of the availability of remarkable wind potential, only $75 \mathrm{MW}$ of wind capacity was in operation at the end of the year 2008 in Estonia. The total energy produced by renewable energy sources in 2008 was $182.4 \mathrm{GWh}$ [5], which is more than $2 \%$ of inland energy consumption. The main problem in the use of wind turbines is high fluctuation of power and accuracy of its forecast. Figure 1 shows hourly power fluctuations and forecast of wind energy in the Estonian power system. The forecast is given daily for the next 24 hours.

The aim of this paper is to analyze the capability of fossil fuel power plant to cover the power forecasting error of WTGs. The aim is also to show that the fuel economy and the reduction of greenhouse gases emissions in the power system consisting of mainly fossil fuel power plants are not pro-

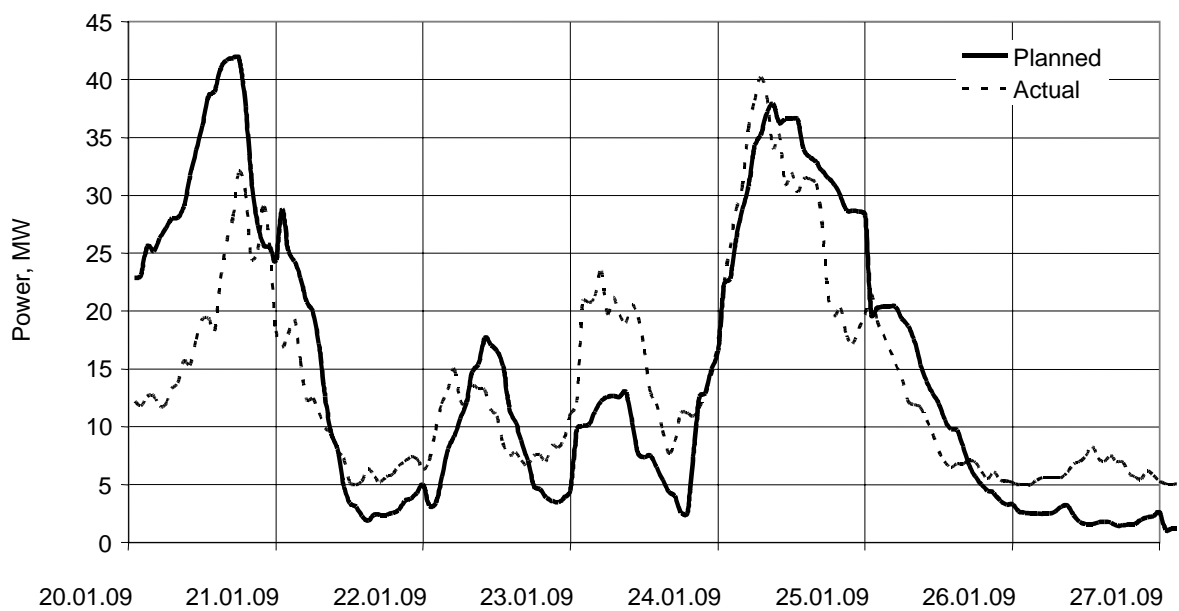

Fig. 1. Planned and actual generation of wind energy in Estonian power system in January 2009 [5]. 
portional to the electricity production of wind turbines. Participation of thermal power plants in the compensation of fluctuating production of wind turbines will reduce the expected positive effect of wind energy.

\section{Problem of balancing wind power fluctuations}

It is well known that the wind power plants are almost uncontrollable, their power varies rapidly and frequently within a wide range. As their output power is the function of wind speed in the third power, their production is hard to forecast and they cause various technical problems and additional investments in the system.

A power curve of wind turbines of Estonia during one week (January 2009) based on the statistical data from [5] is depicted in Fig. 1, and it will serve as an example of the wind energy production and forecast in this paper.

The integration of WTGs into the existing power system is complex and depends on the size and structure of the specific power system and on the capacity of links with neighbouring systems.

Estonia is in a very complicated situation today, where the only local option for balancing wind energy fluctuations is to use large oil-shale based thermal power plants. Nowadays more than $90 \%$ of electricity used in Estonia is oil-shale based.

Combined heat and power (CHP) plants, if not equipped with heat accumulator, follow the thermal load. Large condensing units cannot be stopped and started frequently and for a short period, and their speed of increasing and decreasing the power is limited. Thermal plants most suitable for load regulation and fast reserve capacity are the gas turbines. If someone wants to introduce a large amount of wind power, the power regulating range and speed of the existing plants must be also extensive. The excess energy could be sent over international connections to Finland, Latvia or Russia, but the balancing has to be made anyway when not directly consumed. There is no environmental question in which country the $\mathrm{CO}_{2}$ is emitted.

Fast development of wind energy usage in several countries has brought them to the situation where the balancing of wind power is not easy any more. Publications like [6-8] show that the problems with wind energy expansion that have been discussed only theoretically in Estonia, have become important in the countries which have developed wind power rapidly in practice.

\section{Characteristics of thermal power unit}

To compare the emissions from power systems, we originate from the problem of optimal load dispatch.

The objective of the optimal load scheduling in the power system with thermal power plants and wind generators is the minimization of total fuel cost (can be also fuel consumption or $\mathrm{CO}_{2}$ emissions) at a certain time 
interval. As the balance in the power system must be guaranteed at every moment, the inaccuracy between forecasted and actual wind energy generation must be provided by other means of power plants.

During the constant load or during slow load changes the static inputoutput characteristics of boilers, i.e. the characteristics corresponding to steady state of the unit can be used. If the unit participates in covering rapid changes in the power system, the static characteristics are any longer valid and the dynamic characteristics of boiler must be used. In these conditions the boiler is operating in non-continuous operation. During the rapid increase of load, the relative heat loss with flue gas at boiler exit and relative heat loss due to unburned organic matter increase notably. Due to the above-mentioned reasons the boiler efficiency decreases, and inevitably the relative fuel consumption increases. When the load rapidly diminishes, the losses also occur due to deteriorate burning regime. It is complicated to calculate the precise operation point on dynamic characteristic especially for a fossil-fuel power plant. As the tests of this type are expensive to make and complex to measure, the literature lacks real dynamic characteristics of boilers and large-scale power units. In [9] it is stated that efficiency will be reduced up to $1 \%$ during fast increase, which results in notable increase in cost characteristics. The dynamic and static characteristics based on measurements of a 200-MW thermal unit based on natural gas are presented in [10] and can be seen in Fig. 2. Without knowing the precise dynamic characteristics of the oil-shale power plant, we have assumed it to be higher similarly to a thermal unit based on natural gas. Using the dynamic characteristics gives an opportunity to get more realistic results than the linear methods of calculating fuel consumption and emissions.

Estonian oil-shale power plants contain several double power units, but can also operate as mono power units. Double power units consist of two boilers and a turbine generator and its operation is therefore more flexible.

In the power plant where double power units operate as mono power unit, it is possible to optimize the load dispatch between power units and the unit commitment schedules of power units. In the case of double power unit operation it is also possible to optimize load distribution between the boilers and boilers' commitment schedules. The fuel costs, consumptions and emissions can be read from the corresponding characteristics of thermal plants using calculated optimal powers.

The power plant efficiency is depending on load, and partial-load operation is undesirable because it reduces the engine efficiency [11, 12]. The most effective electricity generation is performed when the unit is operating on a rated load. If we have to balance wind fluctuations, we will have to operate at times on partial load with higher special fuel consumption. Every thermal power plant participating in the compensation operates unefficiently, but balancing reserve must be held. Constant fluctuations in large base load units reduce the lifetime of boilers and increase the frequency of planned maintenance [8]. The emission dependence due to forecast error is presented in [13]. 


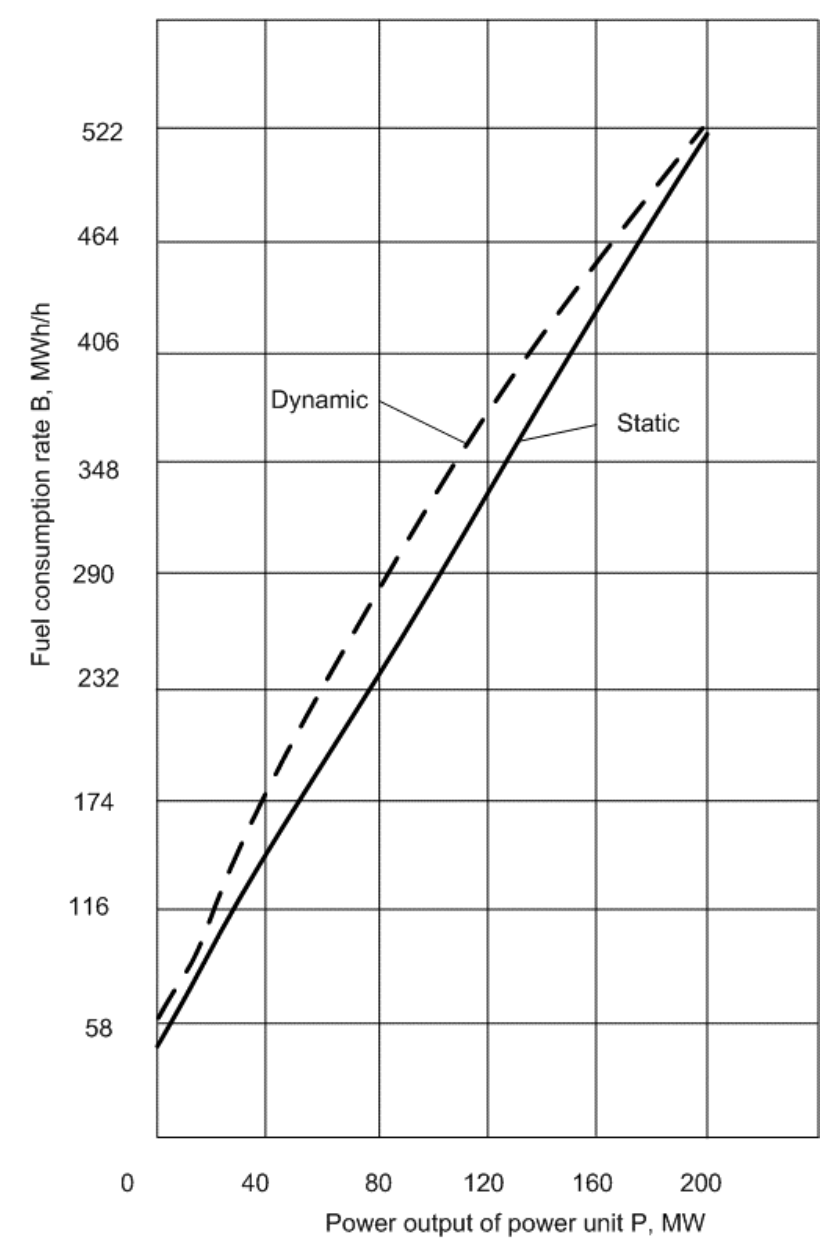

Fig. 2. Static and dynamic characteristic of $200 \mathrm{MW}$ natural gas power unit [10].

If we deal with the necessity of compensating wind power fluctuations with thermal power plants, the fuel cost characteristics must be considered as dynamic values. Under dynamic characteristics the fuel cost in time interval $k$ depends on the power in interval $k$, power in interval $k-1$, and speed and direction of the change of power.

\section{Calculating the environmental effect of wind power}

In Fig. 3 the calculation mechanism of balancing differences between forecasted and actual wind power is presented.

The following reference marks have been used in Fig. 3: $B(P), B^{*}(P)-$ fuel cost static and dynamic characteristics of thermal power plant's balancing unit; $P_{T}^{-}, P_{T}^{+}-$minimum and maximum load permitted for balancing unit; $l$-rate of power deviations (\%) of neighboring time intervals; $k$-index 

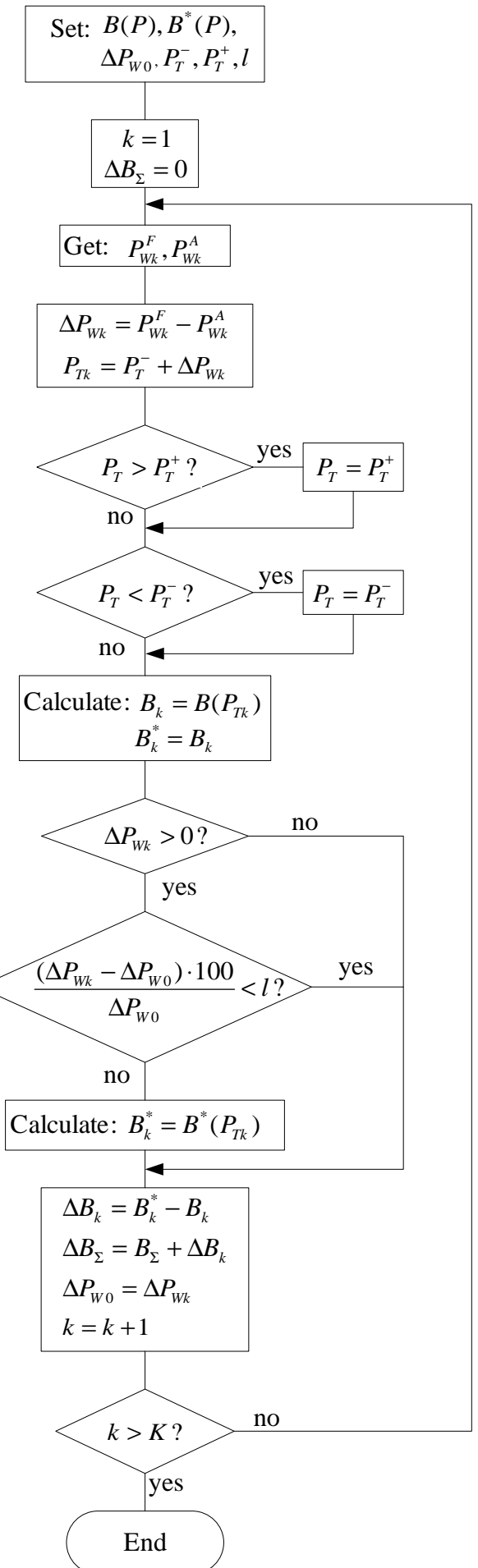

Fig. 3. Algorithm for calculating the fuel overcost of balancing power unit. 
of time interval, $K$-number of time intervals in the given time period; $\Delta P_{W k}, \Delta P_{W 0}$ - wind power forecast error in time interval $k$ and in earlier time interval (i.e. $k-1) ; \Delta B_{k}, \Delta B_{\Sigma}$ - increase of fuel cost in time interval $k$ and in the whole given time period; $P_{W k}^{F}, P_{W k}^{A}$-forecasted and actual total generated wind power generation in time interval $k$.

Forecasted and actual total power generation are real values and taken from the Estonian transmission system operator homepage [5]. The monitored amount of wind turbines at the time of collecting the data was approximately $50 \mathrm{MW}$. The largest wind park (24 MW) was erected and connected to the power system, but was not operating on full power and did not present its forecast.

Wind power forecast errors in the time period are

$$
\Delta P_{W k}=P_{W k}^{F}-P_{W k}^{A}, \quad k=1, \ldots, K .
$$

When the wind power forecast and actual generation differences are negative, i.e. more wind power is generated than predicted, power plant deregulates its generation down to the minimum load $P_{T k}^{-}$. Deregulation of power plant in these calculations is done according to static characteristic. It is assumed that a fast drop in forecast error (predicted and actually generated power are equal or close to each other) does not need covering, and power plant is operating in continuous mode at minimum load.

The wind power forecast error (1) analyzed in this paper can not be larger than investigated power plant's balancing capacity i.e.

$$
\Delta P_{W k} \leq P_{T}^{+}-P_{T}^{-} .
$$

The balancing thermal power plant load is

$$
P_{T k}=P_{T k}^{-}+\Delta P_{W k} .
$$

The boiler is not always operating according to dynamic characteristic. Power plant characteristics depend on forecasting error in MW and can be adjusted by changing the multiplier $l$ within limits from 0 to $100 \%$ of error of previous hour:

$$
\frac{\Delta P_{W k}-\Delta P_{W k-1}}{\Delta P_{W k-1}} \geq l, \quad l \in L=\{0.1 ; \ldots ; 1\} .
$$

As it is not clear, it is taken that when the forecast error in the following hours differs more than a certain percentage (in our calculations $l=0.2$ i.e. $20 \%$ ), for those hours the boiler is operating according to dynamic characteristic.

The calculations are made according to three different versions of dynamic characteristics (with the biggest differences from the static characteristic $1 \%, 5 \%$ or $10 \%$ ), as differences between static and dynamic characteristics vary. 
Two reference scenarios were selected:

- $50 \mathrm{MW}$ scenario - installed wind turbines have to be balanced with oil-shale power plant and installed amount of WTGs corresponds to today's situation;

- 200 MW scenario - installed wind turbines have to be balanced with oil-shale power plant and this amount is currently supported by feed in tariff and will be realistic in 2010 .

Both scenarios are calculated using double and mono power units. For 200 MW scenario the forecasting and actual generation data is the same as for $50 \mathrm{MW}$ scenario, only multiplied by four.

As the forecasted power during the investigated week was relatively low (average wind power output was $14 \mathrm{MWh} / \mathrm{h}$ ) and therefore accurate, there are only some hours with notably large errors. Even though, the total surplus fuel consumption due to dynamic characteristic is up to $1.5 \%$ (see Fig. 4). The main problem is that the power units cannot be stopped during a highwind period even if it turns out that the forecasting has been accurate. During a low-wind period, the unit can be stopped if the low-wind period lasts for days. Frequent starts and stops must be avoided, as these cause extra costs.

These calculations do not take into account the real reduction and increase of wind generation, but just the covering of power differences between forecasted and actual generation. By adding load following the actual overcost could be larger as more fluctuations are taking place. The calculations to see the influence of increased wind penetration into the Estonian power system are presented by Liik et al. in [14].

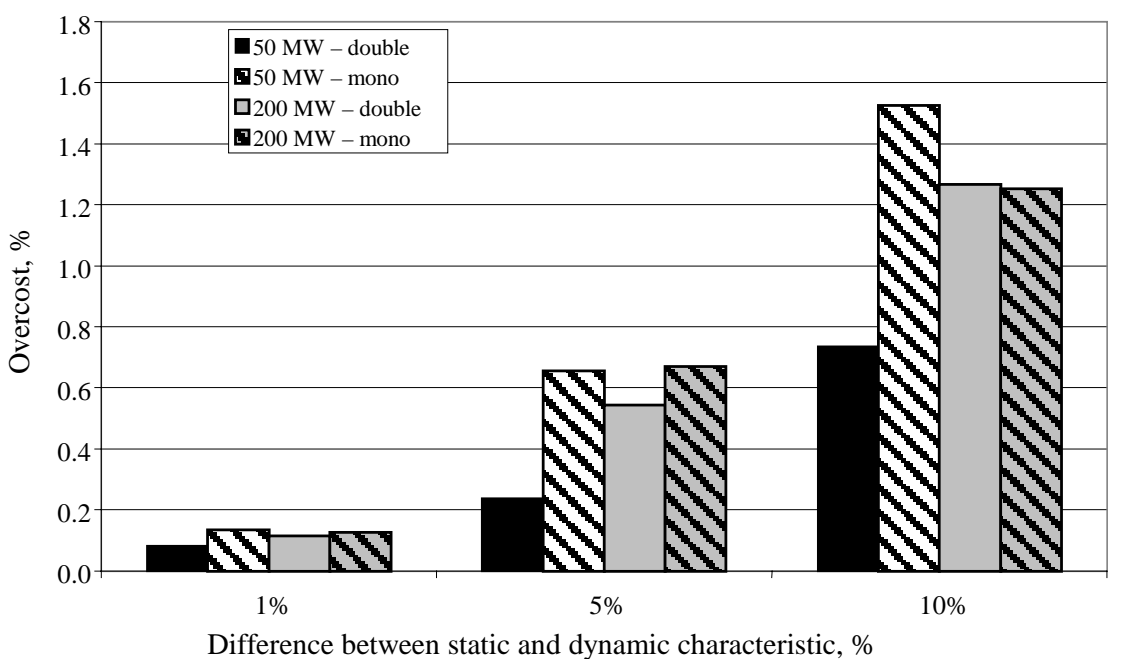

Fig. 4. Oil-shale overcost in thermal power plant due to obligation to balance wind energy. 
In the case of double power unit scenarios the balancing is made for the $180 \mathrm{MW}$ oil-shale power unit with the balancing capability of $100 \mathrm{MW}$, which makes the power plant to work on minimum load at $80 \mathrm{MW}$ when no additional generation is required.

In the case of mono power unit scenarios, the balancing is made for $80 \mathrm{MW}$ oil-shale power unit with the balancing capability of $40 \mathrm{MW}$, which makes the power plant to work on minimum load at $40 \mathrm{MW}$ when no additional generation is required.

Table. Results of balancing of the investigated systems

\begin{tabular}{|c|c|c|c|c|c|c|c|c|c|}
\hline & \multirow[t]{2}{*}{ 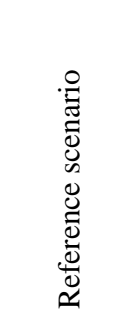 } & \multirow[t]{2}{*}{ 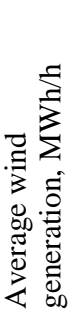 } & \multirow[t]{2}{*}{ 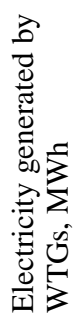 } & \multirow[t]{2}{*}{ 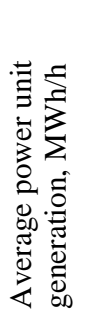 } & \multirow[t]{2}{*}{ 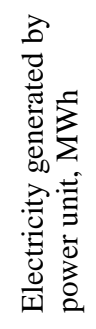 } & \multirow[t]{2}{*}{ 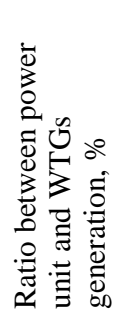 } & \multicolumn{3}{|c|}{ 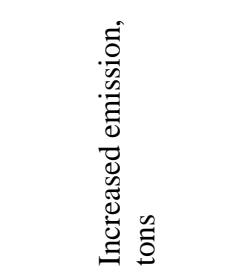 } \\
\hline & & & & & & & $1 \%{ }^{*}$ & $5 \%^{*}$ & $10 \%^{*}$ \\
\hline \multirow{2}{*}{ Mono } & $50 \mathrm{MW}$ & 14 & 2446 & 43.4 & 7900 & 31 & 0.13 & 0.65 & 1.53 \\
\hline & $200 \mathrm{MW}$ & 56 & 9782 & 51.4 & 9354 & 104 & 0.13 & 0.67 & 1.25 \\
\hline \multirow{2}{*}{ Double } & $50 \mathrm{MW}$ & 14 & 2446 & 83.0 & 15180 & 16 & 0.11 & 0.56 & 1.28 \\
\hline & $200 \mathrm{MW}$ & 56 & 9782 & 92 & 17035 & 57 & 0.15 & 0.70 & 1.39 \\
\hline
\end{tabular}

* - Difference between static and dynamic characteristic

It is assumed that the unit is working as a base load unit at minimum load which is generally not reasonable, as pointed out previously. In the calculations 182 hours were analyzed. In the case of $50 \mathrm{MW}$ scenario the double power unit is oversized, but as the balancing is made only in the lower part of cost characteristic, the overcost is lower than it is for the mono power unit. In the case of $200 \mathrm{MW}$ scenario the mono power unit is insufficient, and the maximum power is limited to several hours. In $200 \mathrm{MW}$ and double power unit scenario, the balancing capability in the investigated time period is not entirely used and is sufficient for that amount of wind power. When $200 \mathrm{MW}$ of WTGs are integrated into the Estonian power system, the Estonian target for electricity generated from renewable energy sources should be met, and one double power unit could, in principle, assure the balancing. In every case, the minimum load of a power unit could be raised and balancing range diminished, if less balancing and more base load is required.

Figure 4 depicts the two scenarios based on one-week data, and it can be stated that covering wind energy forecast error with oil-shale power plant increases fuel consumption by 0.2 to $1.5 \%$ depending on the nature of dynamic characteristic. The increase in emitted gases is expected to be of the same extent. 


\section{Conclusions}

Calculations are based on the history of planned and generated wind power and do not take into account uncertainty of the future situation. This uncertainty is the basis for increased fuel consumption as thermal power plants can not be switched off and on as frequently as required for wind power balancing. In the calculations the presented forecasting data to system operator and actual wind power data have been used. The truth is that the real situation is much more complicated and simplifications made within this calculation may differ in both ways from actual values. Taking that into account, it is clear that using fossil fuel power plants for balancing fluctuating wind power causes extra costs due to the following reasons:

- increased fuel consumption due to operation in the inefficient load area (the minimum load point is not the optimal load point),

- surplus fuel consumption due to fast regulation which causes heat loss with flue gas at boiler exit and unburned organic matter,

- extra cost for starting and stopping power plants during long periods of low wind, as fossil fuel based power plants cannot be switched off for some hours,

- increased maintenance cost and reduced lifetime of unit.

Estonia has very good wind resources but there are different technical limitations to its utilization, such as transmission capacity bounds of electrical network and lack of regulating reserves to compensate the fluctuations of wind power. The connection of considerable capacity of wind farms causes smaller positive effect on system efficiency compared to extensive network building and other major investments to the power system.

Participation of thermal power plants, especially the oil-shale ones, in keeping the reserve capacity for wind turbines and in the compensation of wind power fluctuations substantially increases fuel consumption and emissions.

The analysis shows that the use of oil-shale power plant for balancing wind power forecasting error increases fuel consumption and emissions of oil-shale power plants for about $0.5-1.5 \%$, when dynamic characteristic is considered $10 \%$ higher than static one.

Dependence on fossil fuel due to the necessity for balancing remains as long as there is no better large-scale solution introduced.

\section{Acknowledgements}

Authors thank the Estonian Science Foundation (Grant No. 6762) for financial support of this study. 


\section{REFERENCES}

1. US and China in race to the top of global wind industry. Global Wind Energy Council News 02.02.2009. http://www.gwec.net/ (15.02.09).

2. Estonian development plan for the electricity sector 2008-2018 - draft. The Ministry of Economic Affairs and Communications, 26.02.2009. P. 1-50.

3. Wind now leads EU power sector. European Wind Energy Association News 02.02.09. http://www.ewea.org (15.02.09).

4. Kiviluoma, J., Holttinen, $\mathrm{H}$. Impacts of wind power on energy balance of hydro dominated power system. VTT Technical Research Centre of Finland. - Proc. European Wind Power Conference 2006, 27 February - 2 March 2006, Athens, Greece.

5. Estonian transmission system operator. http://www.pohivork.ee (28.01.09).

6. Leonhard, W., Müller, $K$. Balancing fluctuating wind energy with fossil power stations. Where are the limits? // Electra. 2002. Vol. 204. P. 12-17.

7. Lund, $H$. Large-scale integration of wind power into different energy systems // Energy. 2005. Vol. 30, No. 13. P. 2402-2412.

8. Strbac, G., Shakoor, A., Black, M., Pudjianto, D., Bopp, T. Impact of wind generation on the operation and development of the UK electricity systems // Electric Power Systems Research. 2007. Vol. 77, No. 9. P. 1214-1227.

9. Sinkov, V. M., Bogoslovskii, A. V., Grigorenko, V. G. et al. Optimization of Power Systems Operation. - Kiev, 1976 [in Russian].

10. Girschfeld, V., Knjazev, A., Kulikov, V. Operation of Thermal Power Plants. Moscow, 1980 [in Russian].

11. Kaewboonsong, W., Kuprianov, V. I., Chovichien, N. Minimizing fuel and environmental costs for a variable-load power plant (co-)firing fuel oil and natural gas: Part 1. Modeling of gaseous emissions from boiler units // Fuel Process. Technol. 2006. Vol. 87, No. 12. P. 1085-1094.

12. Fragaki, A., Andersen, A. N., Toke, D. Exploration of economical sizing of gas engine and thermal store for combined heat and power plants in the UK // Energy. 2008. Vol. 33, No. 11. P. 1659-1670.

13. Palu, I., Tammoja, H., Oidram, R. (2008). Thermal power plant cooperation with wind turbines // Estonian J. Engineering. 2008. Vol. 14, No. 4. P. 317-324.

14. Liik O., Oidram, R., Keel, M., Ojangu, J., Landsberg, M., Dorovatovski, N. Cooperation of Estonia's oil shale-based power system with wind turbines // Oil Shale. 2005. Vol. 22, No. 2S. P. 127-142.

Received April 29, 2009 